\title{
A FORMAÇÃO DE PROFESSORES PARA EDUCAÇÃO INCLUSIVA NO PORTAL DO PROFESSOR DO MEC: DISCURSO INCLUSIVO X DISCURSO MÉDICO*
}

\author{
Ana Flávia Teodoro de Mendonça Oliveira ${ }^{1}$ \\ Clarissa Martins de Araújo ${ }^{2}$
}

\begin{abstract}
RESUMO: Este artigo analisa as relaçóes de poder-saber produtoras da deficiência nos discursos midiáticos do Portal do Professor do MEC. A partir da perspectiva foucaultiana de análise arqueológica do discurso, constatamos que a produção discursiva sobre a deficiência é realizada de modo híbrido, pois, ao mesmo tempo em que se fundamenta em um discurso inclusivo, que afirma o direito de ser diferente, ataca essa individualidade, fazendo aparecer um sujeito universal, reduzido nas conceitualizaçóes médicas da deficiência. O Portal, ao prescrever práticas pedagógicas que cumpram as metas educacionais propostas pelo Estado brasileiro, pode produzir um efeito contrário, pois muito do que é proposto está atrelado a uma concepção de educação patologizante, o que contraria os pressupostos da inclusão.
\end{abstract}

Palavras-chave: Educação inclusiva. Formação de professores. Portal do Professor do Ministério da Educação.

\section{TRAINING OF TEACHERS FOR ESPECIAL NEEDS EDUCATION IN THE BRAZILIAN MINISTRY OF EDUCATION TEACHER'S WEB PORTAL: INCLUSIVE SPEECH $\times$ MEDICAL SPEECH}

ABSTRACT: This paper aims to analyze the relations of knowledgepower producers of disabilities in the mediatic speech in the Brazilian Ministry of Education Teacher's Web Portal. From Foucault's perspective of archaeological discourse analysis, we found out that the discursive production on disability has been performed in a hybrid mode, because, while it is based in an inclusive speech, it attacks this individuality, by displaying a universal subject, reduced in medical

\footnotetext{
*Esse artigo é um dos resultados do projeto de pesquisa "A Representação Cultural da Deficiência nos Discursos Midiáticos do Portal do Professor do MEC”, desenvolvida no programa de Pós-Graduação em Educação da Universidade Federal de Pernambuco (UFPE), financiada pela Coordenação de Aperfeiçoamento de Pessoal de Nível Superior (CAPES).

${ }^{1}$ Universidade Federal de Goiás, Faculdade de Educação - Goiânia (GO), Brasil.

E-mail: anaflavia_teodoro@hotmail.com

${ }^{2}$ Universidade Federal de Pernambuco, Departamento de Psicologia e Orientação Educacionais e Programa de Pós-Graduação em Educação - Recife (PE), Brasil. E-mail: cmaraujo@ufpe.br

DOI: 10.1590/ES0101-73302017160562
} 
conceptualizations of disability. When prescribes teaching practices that fulfill the educational goals proposed by the Brazilian government, the Portal may produce the opposite effect, because much of what is proposed is linked to a conception of pathologizing education, which contradicts the assumptions of inclusion.

Keywords: Especial needs education. Training of teachers. Brazilian Ministry of Education Teacher's Web Portal.

\section{LA FORMATION DE PROFESSEURS POUR L'ÉDUCATION INCLUSIVE DANS Le Portail du Professeur du Ministère de L'Éducation BRÉSILIEN (MEC) : LE DISCOURS INCLUSIF × LE DISCOURS MÉDICAL}

RESUMÉ: L'article analyse les relations de pouvoir-savoir productrices du handicap dans les discours médiatiques du Portail du Professeur du Ministère de l'Education brésilien (MEC). À partir de la perspective foucaldienne d'analyse archéologique du discours, on a constaté que la production discursive sur le handicap est produite d'une façon hybride, car au même temps qu'il se base sur un discours inclusif qui garantit le droit d'être différent, on attaque cette individualité, et un sujet universel naît, réduit par les conceptualisations médicales du handicap. Le Portail, en prescrivant des pratiques pédagogiques qui accomplissent les objectifs proposés par l'État Brésilien, peut venir à produire un effet contraire, car beaucoup de ce qui est proposé est rapporté à une conception d'éducation "pathologisante ", ce qui contrarie les présupposés de l’inclusion.

Mots-clés: Éducation Inclusive. Formation de professeurs. Portail du Professeur du Ministère de l'Éducation.

\section{Introdução}

A

formação de professores para educaçáo inclusiva tem se tornado uma das prioridades das agendas internacional e nacional, sendo muitas as açôes realizadas no sentido de preparar o professor para lidar com a questão das diferenças. Nesse contexto, em 2008, foi lançado o Portal do Professor do MEC, um espaço de formação permanente, com o objetivo de subsidiar os cursos de capacitaçáo do ProInfo Integrado ${ }^{1}$, bem como proporcionar aos professores, após o término do curso, um ambiente virtual que possibilite aos mesmos se sentirem incluídos em uma comunidade que utiliza as Tecnologias da Informação e Comunicação na Educação

O Portal é constituído por seis grandes áreas - Recursos Educacionais; Espaço da Aula; Jornal do Professor; Área de Cursos; Materiais; e Links - por meio 
das quais busca difundir experiências educacionais das/nas diferentes regióes brasileiras. Também visa a oferecer recursos de multimídia em formatos que atendam às especificidades de cada área e espaços para sugestóes e trocas de experiências entre professores de diferentes locais do Brasil, com formação e interesses distintos. Em seu jornal eletrônico, a plataforma publica eventos e ideias de educadores relacionadas ao cotidiano escolar. Além disso, possui uma revista eletrônica, na qual os professores podem divulgar suas opiniōes e experiências (BIELSCHOWSKY \& PRATA, 2010b).

Diante disso, faz-se necessário ressaltar que, até o ano de 2014, efetuamos uma busca no Portal com o tópico inclusão da pessoa com deficiência. Os conteúdos com essa temática estão presentes em duas edições do Jornal do Professor, 33 vídeos institucionais, além de 769 aulas no Espaço da Aula, evidenciando que há uma grande produtividade de saberes sobre esse sujeito circulando no espaço formativo do Portal, levando-nos a inferir que esse espaço, além de assumir um lugar importante na produção de verdades sobre os referidos sujeitos, também atua instituindo práticas e definindo decisóes pedagógicas de muitos professores.

Dessa forma, fundamentados nos Estudos Culturais de vertente pós-estruturalista, entendemos que as palavras não possuem significados fixos, mas adquirem sentidos ao significar o Outro. Isso nos obriga a desnaturalizar os modos de falar sobre a deficiência, tendo em vista que os discursos que atravessam esse processo formativo resultam de um conjunto de práticas discursivas estabelecidas socialmente e, portanto, a partir de relaçóes de poder. Como nos aponta Larrosa (2002, p. 21):

As palavras com que nomeamos o que somos, o que fazemos, o que pensamos, o que percebemos ou o que sentimos sáo mais que simplesmente palavras. [...] As lutas por palavras, pela imposição de certas palavras e pelo silenciamento ou desativação de outras palavras são lutas em que se joga algo mais do que simplesmente palavras, algo mais do que somente palavras.

No contexto da plataforma, em que discursos são veiculados nos diversos artefatos culturais midiáticos disponibilizados ao professor (Jornal do Professor, Videos Institucionais e Espaço da aula), consideramos relevante analisar as relaçóes de poder-saber produtoras da deficiência, destacando os jogos de correlaçáo de forças que estabelecem critérios de validade e de legitimidade acerca da deficiência, partindo do entendimento de que "todas as práticas de significação que produzem significados envolvem relaçóes de poder, incluindo o poder para definir quem é incluído e quem é excluído" (WOODWARD, 2009, p. 18).

Assim, ao reconhecer a deficiência como objeto cultural e ao definir as relaçôes entre deficiência e poder como elementos centrais de nosso estudo, valemo-nos do pensamento de Michel Foucault. Essa perspectiva teórica ajuda-nos a 
entender que o poder "incita, induz, desvia, facilita ou torna mais difícil, amplia ou limita, torna mais ou menos provável; no limite, ele coage ou impede absolutamente, mas é sempre uma maneira de agir sobre um ou vários sujeitos ativos" (FOUCAULT, 1995, p. 243).

Outrossim, para entendermos como as relaçóes de poder e de saber "perpassam" o sujeito com deficiência, devemos considerar o pensamento do autor:

Temos que admitir que o poder produz saber (e náo simplesmente favorecendo-o porque o serve ou aplicando-o porque é útil); que poder e saber estão diretamente implicados; que não há relação de poder sem constituição correlata de um campo de saber, nem saber que não suponha e não constitua ao mesmo tempo relaçôes de poder. (FOUCAULT, 2009, p. 30).

A partir desse raciocínio, interessa-nos examinar os discursos, presentes no Portal do Professor do MEC, para saber até que ponto eles estáo imbuídos de narrativas que constroem o Outro com deficiência enquanto objeto de conhecimento, em um processo de objetivação científica. Sobre esse processo de objetivação, Larrosa (1994, p. 50) nos diz que:

É no momento em que se objetivam certos aspectos do humano que se torna possível a manipulação técnica institucionalizada dos indivíduos. E, inversamente, é no momento em que se desdobra sobre o social um conjunto de práticas institucionalizadas de manipulação dos indivíduos que se torna possível sua objetivação "científica".

Dessa forma, acreditamos que, ao definir as unidades de análise do discurso - saber, poder e objetivação -, poderemos, de alguma maneira, esmiuçar como se manifesta nos discursos do Portal uma "vontade de saber" sobre as pessoas com deficiência, uma vez que partimos do pressuposto de que tanto a invenção da deficiência quanto sua manutenção são resultados dessa "vontade de saber" sobre os sujeitos com deficiência, que teve e tem, por sua vez, correlação com uma "vontade de poder" sobre esses indivíduos.

\section{Método}

A análise dos discursos que produzem a deficiência na trama discursiva do Portal do Professor do MEC foi realizada com base nos fundamentos da análise arqueológica de Foucault (2013). Sobre essa abordagem, consideramos pertinente apresentar algumas de suas características que nortearam essa etapa da pesquisa, a saber: 
A arqueologia busca definir não os pensamentos, as representaçóes, as imagens, os temas obsessões que se ocultam ou se manifestam nos discursos, mas os próprios discursos, enquanto práticas que obedecem a regras. [...] Não é o retorno ao próprio segredo da origem; é a descrição sistemática de um discurso-objeto (FOUCAULT, 2013, p. 169-170).

Ao realizar a leitura dos textos culturais do Portal, tomamos essas fontes como monumentos a serem desconstruídos e reconstruídos. Portanto, não consideramos os discursos sobre a deficiência como uma verdade sobre esses sujeitos, mas como monumentos de sua construção. Tal análise refere-se a uma leitura que não trata o discurso como documento, mas que "se dirige ao discurso em seu volume próprio, na qualidade de monumento" (FOUCAULT, 2013, p. 170).

Nesse sentido, ao adotarmos essa abordagem como instrumento de análise, queremos salientar que não construímos um corpus de pesquisa, mas sim um arquivo. O arquivo, para Foucault (2013, p. 158), consiste na lei "do que pode ser dito, o sistema que rege o aparecimento dos enunciados como acontecimentos singulares".

Assim, selecionamos textos culturais diversos para o nosso arquivo de pesquisa, posto que, na produção da deficiência, entram em jogo a luta entre vários discursos e a luta pela imposiçáo de sentidos sobre esses sujeitos, fazendo com que as pessoas com deficiência sejam narradas de inúmeras formas e por meio de diferentes modalidades enunciativas, como no discurso dos Videos institucionais, nas matérias veiculadas no Jornal do professor e nos discursos do Espaço da aula destinados a formar o professor.

Diante da multiplicidade do material em análise, para seleção das aulas privilegiamos aquelas relacionadas com a temática "inclusão da pessoa com deficiência". Nessa seleçáo, encontramos sete aulas que falavam sobre a deficiência mental, a deficiência visual, a deficiência física e a deficiência múltipla na escola. Esse conjunto de aulas, se comparadas às outras sobre inclusão, possuíam um grande número de acessos, levando-nos a perceber que a inclusão, para os diferentes tipos de deficiência, é a preocupação da maioria dos professores que conectam o Portal.

Após a definição das aulas, iniciamos outra etapa, em que selecionamos as matérias veiculadas no Jornal do professor sobre a temática da deficiência. Ao explorar esse espaço, constatamos que duas ediçôes tratavam desse tema. Assim sendo, selecionamos a edição Libras na escola e Acessibilidade e inclusão.

Em relação aos vídeos institucionais, fizemos uma busca com a palavra deficiência e encontramos 33 recursos com a respectiva temática. A partir dessa busca, elegemos os recursos que falam sobre a inclusão da pessoa com deficiência, excluindo os destinados a ensinar sobre Libras, Braille ou até mesmo aqueles que 
ensinam a fazer materiais adaptados. Dito isso, apresentamos, no quadro abaixo, os componentes do Portal que constituíram nosso arquivo de análise.

\section{Resultados e discussão}

Para discutir a produção do sujeito com deficiência no Portal e sua imersão no jogo do poder-saber, apresentamos, inicialmente, uma análise do lugar de enunciação da deficiência. Nesse sentido, cabe esclarecer que os lugares de enunciação são instituiçôes que reconhecem tantos os autores quanto os discursos produzidos por esses, sendo também o lugar em que se estabelecem as regras para pronunciação do discurso.

É preciso destacar que o referido espaço formativo, enquanto instituição destinada à capacitação docente, por meio das TICs, recebe o seu estatuto de enunciador privilegiado no âmbito da educação por estar intimamente vinculado ao Ministério da Educação (MEC). Isso significa que as formas de narrar e representar a deficiência são potencializadas pela própria autoridade conferida a esse

\section{Quadro 1}

Arquivos analisados no Portal do Professor do MEC.

\begin{tabular}{|c|c|}
\hline & Arquivo de análise $^{2}$ \\
\hline $\begin{array}{l}\text { Aulas } \\
\text { selecionadas }\end{array}$ & $\begin{array}{l}\text { - A deficiência visual na escola } \\
\text { - Trabalhando a deficiência auditiva } \\
\text { - A deficiência mental na escola } \\
\text { - A deficiência física na escola }{ }^{6} \\
\text { - As deficiências múltiplas na escola }{ }^{7} \\
\text { - Pensando sobre a convivência na escola }{ }^{8} \\
\text { - Diferentes leituras para pessoas com necessidades especiais: Braille, libras e } \\
\text { leitura labial }\end{array}$ \\
\hline $\begin{array}{l}\text { Jornal do } \\
\text { professor }\end{array}$ & $\begin{array}{l}\text { - Acessibilidade e Inclusão - edição } 30 \text { (Escola do Paraná está comprometida } \\
\text { com a inclusão) }{ }^{10} \\
\text { - Acessibilidade e inclusão - edição } 30 \text { (Piauí incentiva a inclusão) }{ }^{11} \\
\text { - Libras na escola - ediçãao } 51 \text { (Escola do Recife atrai estudantes excluídos) }{ }^{12}\end{array}$ \\
\hline $\begin{array}{l}\text { Vídeos } \\
\text { institucionais }\end{array}$ & $\begin{array}{l}\text { - Bem além dos limites (deficiência física) }{ }^{13} \\
\text { - Esporte como fator de inclusão }{ }^{14} \\
\text { - Deficiente Mental: ameaça ou oportunidade }{ }^{15} \\
\text { - Escola, a primeira aventura }{ }^{16}\end{array}$ \\
\hline
\end{tabular}

Fonte: Portal do Professor do MEC 
lugar institucionalizado pelo MEC, tendo em vista que o espaço formativo do Portal recebe a colaboração direta do ministério.

Salientamos também a heterogeneidade dos parceiros encarregados de produzir a materialidade discursiva do Portal, denunciando a complexidade da articulação dos discursos desse espaço formativo. Essa complexidade evidencia-se nas inúmeras contribuições advindas de parceiros múltiplos, tais como os das secretarias do MEC e das secretarias estaduais e municipais de educação.

Nesse contexto, é importante registrar as formas de poder-saber na função enunciativa do referido Portal, uma vez que, como sujeito enunciador, é conferida a esse espaço a legitimidade do saber intelectual ou do saber científico, pelas inúmeras parcerias estabelecidas com universidades públicas nacionais e internacionais. Sobre isso, os dados disponibilizados no Portal revelam que:

Para alcançar os conteúdos pesquisados na internet, constituí-
mos uma parceria com as universidades federais do Ceará, de São
Carlos, do Rio de Janeiro, de Minas Gerais, do Rio Grande do Sul,
a Federal Fluminense, a UNB e a Unespe de Presidente Prudente
[...]. São estabelecidos acordos de colaboraçáo entre instituiçóes
como as Universidades do Colorado, Califórnia e Utah (USA),
Universidade de Alicante (Espanha), Instituto de Tecnologia da
Califórnia (USA), dentre tantos outros (BIELSCHOWSKY \&
PRATA, 2010a).

Além das parcerias com as universidades, o Portal recebe também a colaboração de organismos financeiros internacionais como a Organização das Naçóes Unidas para a Educação Ciência e Cultura (UNESCO) e de algumas instituições privadas e públicas, tais como Fundação Telefônica (Educarede), Bradesco, Vivo, Oi Futuro, Claro, Organização de Estados Ibero-americanos (OEI), Cezar, Instituto Algar e empresas como Intel, Corel, Cisco, Adobe, Microsoft, Agência Espacial Brasileira (AEB) e a Empresa Brasileira de Pesquisa Agropecuária (Embrapa) (BIELSCHOWSKY \& PRATA, 2010b).

O comprometimento do Portal com esse conjunto de forças discursivas, advindas de lugares heterogêneos, demonstra que os discursos sobre a deficiência que circulam nesse espaço formativo estão abertos a diferentes autorias e a afiliaçóes diversas. Nesse sentido, nossa análise permite-nos inferir que os sujeitos que enunciam no Portal se apropriam de discursos sobre a deficiência oriundos do campo da medicina, da psicologia, da pedagogia, do estudo da diversidade e da inclusão, além do campo religioso, de maneira que se ocupam em nomear e narrar essas pessoas, fazendo surgir múltiplas formas de produção cultural da deficiência. No entanto, pela proeminência e regularidade dos discursos, neste artigo optamos por analisar o discurso da Pedagogia Inclusiva e o discurso Clínico-Patológico, fazendo aparecer as relações interdiscursivas que instituem o funcionamento do discurso da deficiência no Portal. 


\section{o Discurso da Pedagogia Inclusiva}

Os discursos sobre a deficiência no Portal são atravessados por enunciados que falam sobre a inclusão desses sujeitos. Portanto, é possível identificar na materialidade textual uma variedade de enunciados em que o tema inclusão da pessoa com deficiência ganha visibilidade, fazendo circular discursos que falam sobre adaptaçóes curriculares, acessibilidade, ofertas de atendimento educacional especializado, formação de professores, dentre outras, como podemos ver nos excertos abaixo:

A escola fez algumas reformas para garantir a acessibilidade: construiu rampas, banheiro especial, e alargou portas. Também se preocupou em garantir a presença de profissionais capacitados para $o$ atendimento de alunos com necessidades educacionais especiais (ESCOLA DO PARANÁ ESTÁ..., 2009).

A próxima meta de Maria de Fátima é montar uma sala de atendimento especializado com equipamentos e jogos que possam contribuir para a melhoria do aprendizado e a inclusão de alunos com diferentes deficiências e necessidades (ESCOLA DO RECIFE ATRAI...,2011).

Examinando as formulaçóes dos professores, é possível dizer que os enunciados sobre a inclusão, engendrados nas materialidades discursivas do Portal, encontram na própria Lei Constitucional Brasileira de 1988 (BRASIL, 1988), na Lei de Diretrizes e Bases da Educação Nacional de 1996 (BRASIL, 1996) e também em documentos internacionais como a Declaração Mundial de Educação para Todos (UNESCO, 1990), a Declaração de Salamanca (UNESCO, 1994), dentre outros, as condiçóes de possibilidade para enunciação da deficiência.

Isso significa que o professor, ao enunciar a respeito da inclusão da pessoa com deficiência, evidenciando sua adesão a esse ideário, está obedecendo a certo regime de verdade de sua época. São justamente essas regras que determinam o feixe de relaçóes que o discurso deve efetuar para poder falar, abordar, analisar, classificar e explicar a deficiência. É por isso que Foucault (2013) afirma que a linguagem nem sempre traduz o querer fundamental daqueles que falam. $\mathrm{O}$ autor explica que:

Isto significa que não se pode falar de qualquer coisa em qualquer época; não é fácil dizer alguma coisa nova; não basta abrir os olhos, prestar atenção ou tomar consciência, para que novos objetos logo se iluminem e, na superfície do solo, lancem sua primeira claridade (FOUCAULT, 2013, p. 54).

É preciso destacar que os enunciados, ao harmonizarem-se com esse regime de verdade, que é a educaçáo inclusiva, estabelecem certas regras, sancionando alguns enunciados e interditando outros tantos. Como consequência disso, 
por vezes, apenas o que se compatibiliza com esse discurso é o que pode ser anunciado. Presumimos que seja essa uma das razóes pelas quais os professores e outros profissionais ligados à área da educação expressam ou revelam uma realidade em que a inclusão das pessoas com deficiência acontece de forma tranquila, natural, sem maiores dificuldades ou entraves, o que se evidencia no discurso abaixo:

A chegada do Anderson, o aluno com paralisia cerebral, levou o colégio a construir um triciclo para que ele pudesse se movimentar facilmente de um ambiente para o outro. Lecionando em oito turmas diferentes, Neide dá aulas para turma do Anderson há três anos. E diz que o trabalho não é difícil (ESCOLA DO PARANÁ ESTÁ...,2009).

Em contrapartida, quando as pessoas com deficiência são autorizadas a narrar a sua própria história de inclusão, delineia-se outro cenário, outra escola é descrita, bem distinta daquela enunciada no discurso dos professores. Como nos alerta Said (1995 apud COSTA, 2005, p. 61), "parece que entre os meandros das histórias para dominar sempre se cria um espaço para algum tipo de escape, alimentado por histórias de contestação e emancipação".

Dentre essas histórias de contestação, encontra-se a de um aluno cadeirante, que explicita em seu discurso o total despreparo da escola, não somente diante das condiçóes de acessibilidade, mas também no que diz respeito ao próprio direito de pertencer, de fazer parte do grupo e de poder ir ao recreio como qualquer outro aluno.

Na hora do recreio eu não posso ir para o pátio por causa da escada e tenho que ficar na mesa da inspetora. Eu falo gente eu não vou cair, e se eu cair o problema não é eu me machucar, o problema é me levantar, o importante é que eu estou indo com vocês, estou querendo participar também. Eu quero participar (MEC, 2009).

Ademais, é interessante sublinhar que, embora o discurso dos professores seja atravessado pelo discurso da inclusão e pelos ideais de igualdade de oportunidades, baseia-se muitas vezes na ideia de que basta estar inserido em sala de aula regular para estar incluso, traduzindo-se em uma concepção integradora em relaçáa à educação da pessoa com deficiência. Vejamos o fragmento abaixo, em que a professora relata a sua prática pedagógica com alunas surdas na sala de aula regular:

Formada em Pedagogia, há dois anos no magistério, Carmem conta que a experiência da inclusão tem sido muito positiva. "No início do ano, as duas estavam muito tristes, muitos quietinhas, mas agora estão mais alegres e participativas". Quando querem se comunicar com a professora elas mandam mensagens, via celular. "É muito gratificante", diz (PIAUÍ INCENTIVA A INCLUSÃO..., 2009). 
Sobre isso, Carvalho (2005) chama atenção para o fato de que inserir os alunos nas escolas comuns, distribuindo-os pelas turmas do ensino regular como figurantes, além de injusto, não corresponde ao que se propóe no paradigma da educação inclusiva. Segundo a autora, a proposta de inclusão é muito mais abrangente e significativa do que o simples fazer parte (de qualquer aluno), e implica, sobretudo, a necessidade de garantir a ativa participação dos alunos com deficiência em todas as atividades do processo de ensino-aprendizagem, principalmente em sala de aula.

O exame breve e pontual do discurso acima coloca-nos diante da necessidade de questionarmos as práticas denominadas inclusivas, que estão sob a égide do discurso da igualdade de oportunidades para todos, uma vez que esse discurso, de certa forma, pode acabar mascarando um processo de inclusáo-excludente.

Obviamente, ao fazermos referência à existência de uma inclusão-excludente, não estamos posicionando-nos contra a inclusão da pessoa com deficiência. O nosso objetivo é problematizar a questão, pois, apesar da existência de um discurso comprometido com os valores da inclusão, existe uma incongruência, ou uma contradição, entre aquilo que o discurso dos profissionais da educação enuncia e o que de fato acontece na escola denominada inclusiva.

O que nos interessa então é compreender qual o significado da inclusão hoje, analisando e discutindo os discursos dos professores, mostrando que esses discursos estâo diretamente implicados com os regimes de saber e poder de sua época e que, exatamente por isso, precisam ser problematizados e desnaturalizados.

Assim, os enunciados do Portal sobre a deficiência parecem demonstrar que, embora sejam textos predominantemente constituídos pelo discurso educacional, eles contêm um sujeito discursivo na ordem do discurso que apaga o saber escolar e evidencia o saber médico, de forma a caracterizar a deficiência.

\section{O Discurso Clínico-Patológico e a objetivação da deficiência}

Ao analisar os textos culturais, percebemos que, para se falar ou para se compreender a deficiência, é preciso primeiramente apresentar de forma sumária um exame de suas causas. A ênfase nas causas da deficiência parece fazer parte de um ritual de exploração da patologia, como podemos verificar nos fragmentos abaixo:

\footnotetext{
Roteiro da pesquisa - Nome da deficiência; esta deficiência é de causa congênita ou adquirida; quais os tipos de tratamento que a pessoa pode fazer; busque dicas para conviver de forma inclusiva com esta pessoa (RODRIGUES et al., 2010).
}

As preocupaçōes dos professores em elucidar as causas da deficiência podem construir uma visão estanque e fragmentada desta, fazendo com que a 
diferença seja percebida apenas como algo inato, produto da natureza e náo como uma construção social. Uma boa alusão sobre isso pode ser encontrada na afirmação de Tomazini (1998, p. 115):

A localização do mal no indivíduo, como fenômeno de causas endógenas, não mobiliza os mecanismos socioculturais na identificação da diferença. Se mudássemos o eixo de visibilidade, a questão seria remetida ao contexto social, à verificação das condiçōes que conferem a determinados comportamentos a significação de desvio, e reconhecer nos atos "doentes", "marginais", "desadaptados", a marca sociocultural.

No discurso médico, os sujeitos com deficiência são significados a partir de suas incapacidades, de suas limitações e supostas "faltas". Tais discursos são presos à lógica da vitimização, marcados pelos inúmeros "não podem" ou "não conseguem", realimentando a imagem de pessoas com deficiência como eternos sofredores ou vítimas de seu destino biológico. A surdez, por exemplo, é representada nos discursos do Portal como sinônimo de falta e limitaçáo, sugerindo que tal condição torna o sujeito incapaz de interagir com o mundo, devido às limitaçóes decorrentes da perda da audição e dos problemas decorrentes da linguagem.

As pessoas surdo-mudas estão desprovidas de sua fala e de sua audição. Por esse motivo, a sua interação com o mundo está seriamente comprometida. Esse fato torna limitado o seu convívio social, tornando-as mais dependentes e dificultando-as de exercerem a sua cidadania. (TEIXEIRA; FAGUNDES, 2010

Obviamente não podemos desvincular a surdez da falta da audição; contudo, afirmar que os surdos são limitados, que não conseguem interagir com o mundo social ou exercer a sua cidadania é um grande equívoco, que tem como consequência a construção de significados que colocam os surdos em uma posição de subalternidade em relação à comunidade ouvinte. Sobre a representação da surdez como falta, Thoma (2002, p. 244) esclarece que:

A leitura da surdez como falta está presente na história da surdez e dos surdos, contada a partir dos que ouvem [...]. Nomeando, narrando, descrevendo a alteridade surda a partir de um viés "faltante", os significados da normalidade mantêm e ampliam a fixaçáo dos surdos como sujeitos inferiores aos que ouvem.

A perspectiva clínica se materializa, também, por meio de todo um conjunto de enunciados que buscam conceituar a deficiência, fazendo parecer que só se pode conhecer a pessoa, ou o aluno, se soubermos compreender ou conceituar 
a sua deficiência. A estratégia utilizada pelos enunciadores do Portal configura-se como uma tentativa de definir a deficiência a partir de padróes preestabelecidos definidos pelo discurso científico, como veremos abaixo:

A deficiência mental é caracterizada por um funcionamento intelectual significativamente inferior à média, com manifestaçôes antes dos dezoito anos e limitaçóes associadas a duas ou mais áreas de habilidades adaptativas, tais como: comunicação; cuidados pessoais; habilidades sociais; saúde e segurança; lazer e trabalho. (RODRIGUES; DOSCHER; DOSCHER, 2010).

Consideramos que a conceituação da deficiência pode ser entendida como uma forma de exame, uma vez que, nessa técnica específica, estão comprometidos todo um campo de saber e todo um tipo de poder que permitem obter e constituir saberes sobre os sujeitos com deficiência, estabelecendo sobre eles "um controle normalizante, uma vigilância que permite qualificar, classificar e punir" (FOUCAULT, 2009, p. 177).

A conceituação da deficiência fixa as diferenças individuais desses sujeitos, dando a impressão de que eles são uma massa amorfa, destituída de identidade e individualidade. Sendo assim, a pessoa com deficiência deixa de ser um indivíduo e se transforma em um "caso" que, ao mesmo tempo, constitui um objeto para o conhecimento e uma tomada para o poder. Em relação ao "caso", Foucault (2009, p. 183) salienta que:

\begin{abstract}
Não é mais, como na casuística ou na jurisprudência, um conjunto de circunstâncias que qualificam um ato e podem modificar a aplicação de uma regra, é o indivíduo tal como pode ser descrito, mensurado, medido, comparado a outros e isso em sua própria individualidade; e é também o indivíduo que tem que ser treinado ou retreinado, tem que ser classificado, normalizado, excluído etc.
\end{abstract}

Destarte, o grande perigo da conceituação é que, ao esmerar-se em descrever as pessoas com deficiência, institui-se também o olhar do professor em formação, que pode começar a ver esses sujeitos a partir de um mecanismo ótico patologizante. Assim, compreendemos que o conceito de deficiência funciona como um dispositivo de visibilidade, que estabelece, ao mesmo tempo, o que é a pessoa com deficiência, enquanto objeto visível, e determina a visão do professor em relação a esse aluno. Sobre essa questão, Larossa (1994, p. 58) esclarece que:

Um regime de visibilidade composto por um conjunto específico de máquinas óticas abre o objeto ao olhar e abre, ao mesmo tempo, o olho que observa. Determina aquilo que se vê ou se faz 
ver, e o alguém que vê ou que faz ver. Por isso o sujeito é uma funçáo da visibilidade, dos dispositivos que o fazem ver e orientam seu olhar. E esses são históricos e contingentes.

Torna-se, portanto, de grande importância refletir sobre as conceituaçóes médicas da deficiência encontradas nos textos culturais do Portal, tendo em vista que, nessas conceituaçóes, a noção ou a definição da deficiência é contingente, provisória e, por sua vez, datada. Sobre isso, Amaral (1998, p. 24) esclarece que:

Ao nos debruçarmos sobre um conjunto conceito/definição, é imprescindível lembrar que essa díade é sempre historicamente datada. [...] Penso que o conceito de deficiência e sua definição passam por dimensôes descritivas e por dimensōes valorativas, tendo sempre um caráter histórico concreto: um determinado momento, num contexto socioeconômico-cultural específico.

O grande problema desse tipo de abordagem é o perigo de que a deficiência se torne categorial, estática, que não possibilite aos professores em formação repensar dimensóes particulares da deficiência à medida que os contextos e as circunstâncias mudam. Ao objetivar a deficiência por meio de um saber médico, tomando-a como objeto natural, corre-se o risco de considerá-la como algo puramente pessoal, e não como algo implicado na dinâmica social e política vigente.

Ademais, é importante sublinhar que a presença do saber médico, naquilo que diz respeito às pessoas com deficiência, pode obscurecer questóes importantes a serem discutidas nos processos formativos, a saber: o processo de inclusão desses sujeitos, a acessibilidade, o uso de tecnologia assistiva, a prática pedagógica, a empregabilidade dos sujeitos com deficiência, entre tantas outras.

De fato, concordamos com Skliar (2006) quando ele afirma não compactuar com as ideias atuais de formação que conservam intactas as mesmas estratégias e os mesmos textos criticados desde sempre, pois as consideram como invençôes, estereótipos, traduções e fixações da alteridade. Para ele, esses são modos coloniais referentes ao outro, seja quem for esse outro, tido como incompleto, insuficiente, o qual deve ser corrigido.

Acreditamos, nesse ponto, que é preciso reformular a própria relação com o Outro com deficiência nos processos formativos, desvencilhando-nos dos discursos que buscam colonizar a deficiência, exercendo uma lógica perversa em que esses sujeitos devem ser apresentados em detalhes, contados em seus desvios patológicos e medidos em suas capacidades.

Tais consideraçóes evidenciam que esses tipos de propostas devem ser questionados, uma vez que se produz um verdadeiro jogo de objetivação da de- 
ficiência, levando os docentes a pensar o sujeito com deficiência segundo parâmetros médicos - causas, tratamentos, capacidades cognitivas, relação interpessoal e inserção social, habilidades acadêmicas e de comunicação - conferindo a eles o status de doente, o que contribui para a construção de uma visão totalizadora e essencializada da deficiência.

\section{Considerações finais}

Ao analisar a produção do sujeito com deficiência no Portal do Professor do MEC e a sua imersão no jogo entre deficiência e poder, constatamos que sobre a deficiência incidem forças advindas de vários campos de saber, poderes capilarizados e formas de condução que recaem sobre todos os âmbitos da vida dos sujeitos com deficiência.

Nessas diferentes maneiras de narrar a deficiência, observamos inicialmente que os docentes, efetivamente, demonstram uma adesão ao discurso da inclusão, mostrando-se engajados ao projeto educacional e às propostas de uma educação para todos. Sendo assim, observamos a conformação docente a um conjunto de regras, aos sistemas de pensamento, às diretrizes, aos estatutos e às leis que apregoam a educação inclusiva, demonstrando que, ao narrarem a deficiência, os docentes obedecem a um conjunto de práticas discursivas e não discursivas que compóem jogos de verdade sobre as pessoas com deficiência.

Nessa perspectiva, as regras do discurso pela inclusão, como definidoras do regime de verdade dos discursos docentes, promovem interdiçóes no seio da própria formação discursiva, organizando a maneira de os professores falarem, o que coloca em ação uma gramática própria, fazendo com que apenas aquilo que se harmoniza com os enunciados em prol de uma educaçáo inclusiva seja o que pode efetivamente ser dito.

Uma das consequências disso é que, ao enunciar as "verdades" a respeito da deficiência, os docentes não problematizam as situações de preconceitos, as intolerâncias vividas em sala de aula e, até mesmo, as fragilidades do processo de educação inclusiva. Pelo contrário, os professores tornam evidentes apenas os aspectos positivos da inclusáo, demonstrando que a educaçáo inclusiva tem acontecido de forma natural, sem grandes tensóes e entraves.

Dessa maneira, nesse jogo de poder-saber, quando os sujeitos com deficiência são autorizados a narrar sua própria história de inclusão, delineia-se outro cenário, completamente distinto do que foi enunciado pelos docentes, tornandose perceptível a existência de uma inclusão por vezes excludente. Essa inclusão-excludente torna-se explícita por meio das narrativas discentes, que colocam em evidência as situações de falta de acessibilidade, de descaso em relação à importância do intérprete na sala de aula regular e de tantas outras circunstâncias que 
denunciam o despreparo da escola e do professor para, efetivamente, promoverem uma educação inclusiva de qualidade.

As histórias de contestação tecidas pelos sujeitos com deficiência e o silenciamento dos professores em relação às dificuldades enfrentadas na realização do processo educacional inclusivo evidenciam o quanto os docentes estão regulados em seu poder de dizer sobre a deficiência e o quanto os seus enunciados estão permeados por relaçóes de controle e dominação, ajustandose, portanto, às dinâmicas de poder e saber de seu tempo. Isso tem implicações profundas na formação de professores para educação inclusiva, entre elas, a suposição de que a inclusão se faz apenas pela inserção dos sujeitos com deficiência na sala de aula regular, simplificação que pode imobilizar e impossibilitar reflexóes sobre alternativas para as situaçóes de desigualdade e exclusão desses sujeitos na escola regular.

Em contrapartida, embora os docentes fundamentem-se em um discurso inclusivo, que apregoa o direito de ser diferente, contrapóem-se a essa individualidade, produzindo-se um sujeito universal, reduzido nas conceituaçóes médicas da deficiência. A forte ênfase na conceituação dos sujeitos com deficiência acaba posicionando-os como objetos legítimos da ciência e dos aparatos de normalização. Dessa maneira, o corpo desses sujeitos se presta à observação. Com essa forma de "exame", são projetadas suas identidades e são prescritos os tratamentos que esses sujeitos merecem ter, ou seja, que produzem quem ele é, como agem e como devem ser tratados.

Tal discurso é problemático, pois, no afã de significar a deficiência por meio das conceituaçôes, com a descrição dos sujeitos e com a procura por universais nos seus comportamentos, reduz-se a historicidade dessas pessoas em todas as suas dimensóes, fazendo parecer que existe uma suposta essência verdadeira intrínseca a esses indivíduos. Sob esse enfoque, devemos considerar que os professores em formação, ao serem regidos pelos conceitos médicos da deficiência, em um jogo de objetivação, acabam regulados e disciplinados na forma de pensar os sujeitos com deficiência, bem como na maneira de agir com relação a e sobre eles. Isso contribui para que o docente construa um diagnóstico prévio das "competências" e "incompetências" ou das "capacidades" e "incapacidades" das pessoas com deficiência.

Nesse procedimento disciplinar, estão comprometidos todo um campo de saber e todo um tipo de poder que estabelecem aos indivíduos com deficiência uma visibilidade obrigatória, por meio da qual eles são diferenciados e sancionados. Em outras palavras, ao conceituar a deficiência, colocam-se aqueles indivíduos em um campo de vigilância, situando-os em uma rede de anotaçóes escritas que os captam, os vigiam, os registram, os individualizam e buscam produzir saberes sobre os sujeitos com deficiência, concebendo-os como um produto da biologia, fixando suas identidades. 
Dessa forma, é possível afirmar que o discurso do Portal ainda persiste na produçáo da deficiência de maneira pejorativa e estereotipada, fazendo com que o sujeito com deficiência, na sua multiplicidade e diferença, seja substituído por uma construção imaginária que, por vezes, não tem nenhuma relação com a realidade. Isso ocorre a despeito do fato de que o Portal é capaz de atrair os professores pelas possibilidades de intervenção e de transformação das suas práticas pedagógicas, por meio do conjunto heterogêneo de técnicas que utiliza; e de produzir a identificação desses profissionais com metas, desejos, anseios e alternativas para mudanças no processo de ensino-aprendizagem de alunos(as) com deficiência. Além disso, o Portal é subsidiado pelo Ministério da Educaçáo e estabelece acordos colaborativos com universidades no Brasil e no exterior, o que confere legitimidade no seu poder de enunciação.

\section{Notas}

1. O ProInfo Integrado é um programa de formação voltado para o uso didático-pedagógico das Tecnologias da Informação e Comunicação (TIC) no cotidiano escolar, articulado à distribuição dos equipamentos tecnológicos nas escolas e à oferta de conteúdos e recursos multimídia e digitais oferecidos pelo Portal do Professor, pela TV Escola e DVD Escola, pelo Domínio Público e pelo Banco Internacional de Objetos Educacionais". BRASIL/MINISTÉRIO DA EDUCAÇÃO, 2016. Disponível em <http://portal.mec.gov.br/component/content/article?id=13156:proinfo-integrado $>$. Acesso em: 23 fev. 2016.

2. Todos os links foram acessados em: 20 nov. 2016.

3. Disponível em: http://portaldoprofessor.mec.gov.br/fichaTecnicaAula.html?aula=19564.

4. Disponível em: http://portaldoprofessor.mec.gov.br/fichaTecnicaAula.html?aula=20449.

5. Disponível em: http://portaldoprofessor.mec.gov.br/fichaTecnicaAula.html?aula=19685.

6. Disponível em: http://portaldoprofessor.mec.gov.br/fichaTecnicaAula.html?aula=19504.

7. Disponível em: http://portaldoprofessor.mec.gov.br/fichaTecnicaAula.html?aula=19577.

8. Disponível em: http://portaldoprofessor.mec.gov.br/fichaTecnicaAula.html?aula=33455.

9. Disponível em: http://portaldoprofessor.mec.gov.br/fichaTecnicaAula.html?aula=18686.

10.Disponível em: http://portaldoprofessor.mec.gov.br/conteudoJornal.html?idConteudo=886.

11.Disponível em: http://portaldoprofessor.mec.gov.br/conteudoJornal.html?idConteudo=887 .

12.Disponível em: http://portaldoprofessor.mec.gov.br/conteudoJornal.html?idConteudo=1567.

13.Disponível em: http://portaldoprofessor.mec.gov.br/fichaTecnica.html?id=18957.

14.Disponível em: http://portaldoprofessor.mec.gov.br/fichaTecnica.html?id=18422.

15.Disponível em: http://portaldoprofessor.mec.gov.br/fichaTecnica.html?id=18961.

16.Disponível em: http://portaldoprofessor.mec.gov.br/fichaTecnica.html?id=18945. 


\section{Referências}

AMARAL, L.A. Sobre crocodilos e avestruzes: falando de diferenças físicas, preconceitos e superação. In: AQUINO, J.G. Diferenças e preconceitos na escola: alternativas teóricas e práticas. 2. ed. São Paulo: Summus, 1998. p. 11-30.

BIELSCHOWSKY, C.E.; PRATA, C.L. Portal Educacional do Professor do Brasil. Revista de Educación, n. 352, maio/ago. 2010a. Disponível em: shttp:// portaldoprofessor.mec.gov.br/storage/materiais/0000013441.pdf $>$. Acesso em: 23 fev. 2016

Portal do Professor do Brasil. Revista de Educación, Espanha, n. 352, p. 617-637, maio/ago. 2010b. Disponível em: <http://www.revistaeducacion.educacion.es/re352 experiencias.htm $>$. Acesso em: 8 nov. 2016.

BRASIL. Constituição da República Federativa do Brasil. Brasília: Senado Federal, 1988.

Lei n. ${ }^{\circ}$ 9.394, de 20 de dezembro de 1996. Estabelece as diretrizes e bases da educação. Diário Oficial da União, Brasília, 23 dez. 1996. Seção 1, 27833-27841.

CARVALHO, R.E. Removendo barreiras para a aprendizagem: educação inclusiva. Porto Alegre: Mediação, 2005.

COSTA, M.V. Currículo e política cultural. In: COSTA, M.V. (Org.). O currículo nos limiares do contemporâneo. 4. ed. Rio de Janeiro: DP\&A, 2005. p. 37-67.

ESCOLA DO PARANÁ ESTÁ COMPROMETIDA COM A INCLUSÃO. Jornal do Professor, 2009, n. 30.

ESCOLA DO RECIFE ATRAI ESTUDANTES EXCLUÍDOS. Jornal do Professor, 2011, n. 51.

FOUCAULT, M. Arqueologia do saber. Tradução de Luiz Felipe Baeta Neves. 7. ed. Rio de Janeiro: Forense Universitária, 2013.

. O sujeito e o poder. In: DREYFUS, H.; RABINOW, P. Michel Foucault, uma trajetória filosófica: para além do estruturalismo e da hermenêutica. Rio de Janeiro: Forense Universitária, 1995. p. 231-249.

Vigiar e punir: nascimento da prisão. Tradução de Raquel Ramalhete. 37. ed. Petrópolis: Vozes, 2009.

LARROSA, J. Notas sobre a experiência e o saber da experiência. Revista Brasileira de Educação, Rio de Janeiro, n. 19, p. 20-28, 2002.

. Tecnologias do eu e educação. In: SILVA, T.T. O sujeito da educação. Petrópolis: Vozes, 1994. p. 35-86.

MINISTÉRIO DA EDUCAÇÃO E DO DESPORTO (MEC). Bem além dos limites: deficiência física. 2009, $15 \mathrm{~min} 24$.

ORGANIZAÇÃO DAS NAÇÓES UNIDAS PARA A EDUCAÇÃO, A CIÊNCIA E A CULTURA (UNESCO). Conferência mundial sobre educação para todos. Tailândia: Jontiem, 1990. Disponível em: <www.unesco.org.br>. Acesso em: 23 out. 2012. 
Declaração de Salamanca e enquadramento da ação na área das necessidades educativas especiais. In: CONFERÊNCIA NACIONAL SOBRE NECESSIDADES EDUCATIVAS ESPECIAIS: ACESSO E QUALIDADE. Salamanca: UNESCO, 1994.

PIAUÍ INCENTIVA A INCLUSÃO EM SUAS ESCOLAS. Jornal do Professor, 2009, n. 30.

RODRIGUES , P. A. A. et al. As deficiências múltiplas na escola. Portal do Professor do MEC, Espaço da Aula. 2010. Disponível em: <http://portaldoprofessor.mec.gov.br/ fichaTecnicaAula.html?aula=19577>. Acesso em: 20 nov. 2016.

RODRIGUES, P. A. A.; DOSCHER, A. L.; DOSCHER, E.. A deficiência mental na escola. Portal do Professor do MEC, Espaço da Aula. 2010. Disponível em: <http:// portaldoprofessor.mec.gov.br/fichaTecnicaAula.html?aula $=19685>$. Acesso em: 20 nov. 2016.

SKLIAR, C. A inclusão que é nossa e a diferença que é do "outro". In: RODRIGUES, D. (Org.). Inclusão e educação: doze olhares sobre a educação inclusiva. São Paulo: Summus, 2006. p. 15-34.

TEIXEIRA, J. A. T.; FAGUNDES, A. V. Diferentes Leituras para pessoas com necessidades especiais: Braille, Libras e leitura labial. Portal do Professor do MEC, Espaço da Aula. 2010. Disponível em: shttp://portaldoprofessor.mec.gov.br/fichaTecnicaAula. html?aula=18686>. Acesso em: 20 nov. 2016.

THOMA, A.S. O cinema e a flutuação das representaçôes surdas: "Que drama se desenrola neste filme? Depende da perspectiva...”. Tese (Doutorado em Educação)-Programa de PósGraduação em Educação, Faculdade de Educação, Universidade Federal do Rio Grande do Sul, Porto Alegre, 2002.

TOMAZINI, M.E.A. Expatriação social e segregação institucional da diferença: reflexóes. In: BIANCHETTI, L.; FREIRE, I.M. (Orgs.). Um olhar sobre a diferença: interação, trabalho e cidadania. Campinas: Papirus, 1998. p. 111-133.

WOODWARD, K. Identidade e diferença: uma introdução teórica e conceitual. In: SILVA, T.T. (Org.). Identidade e diferença. Petrópolis: Vozes, 2009. p. 7-72.

Recebido em 12 de dezembro de 2016.

Aceito em 14 de março de 2017. 